OPEN ACCESS

International Journal of Environmental Research and

Public Health

ISSN 1660-4601

www.mdpi.com/journal/ijerph

Article

\title{
Built Environmental Correlates of Walking and Cycling in Dutch Urban Children: Results from the SPACE Study
}

\author{
Sanne I. de Vries ${ }^{1,2, *}$, Marijke Hopman-Rock ${ }^{1,2}$, Ingrid Bakker ${ }^{1,2}$, Remy A. Hirasing ${ }^{3}$ and \\ Willem van Mechelen ${ }^{2,3}$
}

1 Department of Health Promotion, TNO Quality of Life, Wassenaarseweg 56, 2301 CE Leiden, The Netherlands; E-Mails: marijke.hopman@tno.nl (M.H.-R.); ingrid.bakker@tno.nl (I.B.);

2 Body@Work TNO VUmc,, EMGO Institute for Health and Care Research, VU University Medical Center, Van der Boechorststraat 7, 1081 BT Amsterdam, The Netherlands

3 Department of Public \& Occupational Health, EMGO Institute for Health and Care Research, VU University Medical Center, Van der Boechorststraat 7, 1081 BT Amsterdam, The Netherlands; E-Mails: ra.hirasing@vumc.nl (R.A.H.); w.vanmechelen@vumc.nl (W.v.M.)

* Author to whom correspondence should be addressed; E-Mail: sanne.devries@ tno.nl; Tel.: +31-71-518-1676; Fax: +31-71-518-1903.

Received: 26 February 2010; in revised form: 28 April 2010 / Accepted: 30 April 2010 / Published: 6 May 2010

\begin{abstract}
This study examined built environmental correlates of children's walking and cycling behavior. Four hundred and forty-eight children from 10 Dutch neighborhoods completed a seven-day physical activity diary in which the number of walking and cycling trips for transportation, to school, and for recreation were assessed. The associations between observed built environmental characteristics and children's walking and cycling behavior were examined with multivariate linear regression analyses. The results showed that built environmental correlates of children's walking and cycling behavior differ by purpose and by commuting mode implying a behavior-specific approach for interventions and for future, preferably prospective, studies.
\end{abstract}

Keywords: walking; bicycling; physical activity; urban design; infrastructure; child; linear regression 


\section{Introduction}

Trend studies suggest a worldwide decline in children's physical activity level, including active transportation [1]. In the last decades, an increasing proportion of children are being transported to school by car [2-4]. Although walking and cycling to school are associated with an increased level of overall active transportation, physical activity, energy expenditure, and cardiovascular fitness [5,6], active transportation to school has long been an overlooked source of daily physical activity for children [7]. However, during the past five years it has become one of the main components of strategies to increase children's overall physical activity level [1].

In order to develop effective strategies that promote active transportation among children, determinants need to be understood. Social ecological models are increasingly being used to gain an insight in the role of the built environment in walking and cycling [8]. In studies using these models, active transportation has been found to be associated with street connectivity [9-11], land use mix [12], distance to a destination [12,13], steep inclines [11], neighborhood safety (e.g., windows facing the street) [11,14-16], traffic safety (e.g., heavy traffic, traffic lights, pedestrian crossings, and limited public transport) [9-11,15,17-19], neighborhood aesthetics [14,18], presence of street trees [12], and facilities near home (e.g., walking and cycling trails, stores, parks, and sports fields) [13]. Most of these studies have been performed in the United States and Australia [13,21]. Built environmental correlates found in these continents cannot easily be generalized to the Netherlands or other European countries [13,22,23]. The Netherlands has a different land-use pattern, geared to the needs of pedestrians and cyclists. Most Dutch children live within five kilometers from elementary school [24,25] and walk or cycle to it [26]. In countries in which distance is not a barrier for active transportation [9], other built environmental characteristics may be important, such as the presence of green space and water in the neighborhood, the absence of garbage and dog waste, and the walking and cycling infrastructure (e.g., cycle-tracks, zebra crossings, roundabouts, parallel parking spaces, and 30-km speed zones) [22].

Built environmental characteristics that correlate with children's walking and cycling behavior may not only be 'country or continent specific', but also 'purpose specific'. For example, studies among adolescents and adults have shown different built environmental correlates of walking and cycling for transportation than that of walking and cycling for recreation [27-29]. Among children, few environmental studies have focused on active transportation to other destinations than school or on recreational walking and cycling [5,13]. In addition, correlates of walking and cycling may also be 'behavior specific', thus built environmental correlates of walking may be different from those of cycling [23,30]. To our knowledge no studies exist that have examined the association between built environmental characteristics and children's walking and cycling behavior separately for walking and for cycling. Therefore, this study aimed to identify built environmental correlates of (a) walking and cycling for transportation, (b) walking and cycling to school, and (c) walking and cycling for recreation among a sample of Dutch children. Furthermore, it was examined whether built environmental correlates of walking are different from those of cycling. 


\section{Methods}

\subsection{Study Design and Study Population}

This study is part of the Spatial Planning and Children's Exercise (SPACE) study [22], a study in which cross-sectional data were collected among a convenience sample of six to 11-year-old children from 10 disadvantaged neighborhoods in six cities in the Netherlands. Table 1 shows some general characteristics of the 10 neighborhoods. Five of the 10 neighborhoods were selected from a list of 56 disadvantaged neighborhoods designated by the government for spatial restructuring. Besides, five neighborhoods were included to investigate the effects of changes in the built environment on children's physical activity in the future. Neighborhood selection criteria were inclusion of pre- and post-World War II neighborhoods, variation in the type of residences and the amount of green space between the neighborhoods, and presence of at least two elementary schools per neighborhood. Neighborhood boundaries were defined by city councils. The 10 neighborhoods varied in size and in population density. The children who lived in these neighborhoods and who were between six and 11-years old were recruited from 20 elementary schools (two schools per neighborhood). Children in this age group were studied, because they are more likely to have a radius of action for their daily physical activities that corresponds with the size of their neighborhood than younger children who have a smaller radius of action (i.e., one block of houses) or older children who have a larger radius of action (i.e., several neighborhoods) [31]. Informed consent was obtained from the parents of 1,228 children. All measurements were conducted between October 2004 and January 2005. The study was approved by the ethics committee of the Leiden University Medical Center.

Table 1. General characteristics of the 10 Dutch neighborhoods.

\begin{tabular}{|l|c|c|c|}
\hline \multicolumn{1}{|c|}{ Neighborhood } & Main construction period & $\begin{array}{c}\text { Size } \\
\text { (hectare) }\end{array}$ & $\begin{array}{c}\text { Population density } \\
\text { (residents/ km }\end{array}$ \\
\hline 1. Delftwijk, Haarlem & post-WW II & 51 & 8,646 \\
\hline 2. Molenwijk, Haarlem & post-WW II & 228 & 4,390 \\
\hline 3. Spangen, Rotterdam & pre-WW II & 65 & 16,278 \\
\hline 4. Nieuwe Westen, Rotterdam & pre-WW II & 124 & 15,076 \\
\hline $\begin{array}{l}\text { 5. Randenbroek-Schuilenburg, } \\
\text { Amersfoort }\end{array}$ & post-WW II & 215 & 5,511 \\
\hline 6. Liendert, Amersfoort & post-WW II & 105 & 7,234 \\
\hline 7. Groenoord, Schiedam & post-WW II & 110 & 7,955 \\
\hline 8. Holy-Zuid, Vlaardingen & post-WW II & 190 & 5,871 \\
\hline 9. Berflo Es, Hengelo & pre-WW II & 110 & 5,391 \\
\hline 10. Wilderinkshoek-Tuindorp, & pre-WW II & 102 & 4,703 \\
\hline
\end{tabular}




\subsection{Dependent Variables: Walking and Cycling}

Walking and cycling were assessed by a validated seven-day physical activity diary [32], which was completed by one of the parents together with their child. During seven consecutive days for all waking hours, all physical activities were noted at the end of each day, including the duration of the activity and one of the following corresponding physical activity categories: active transportation, activities during school time, organized sports, playing outdoors, and activities at home. For each day, the number of walking and cycling trips were summed, distinguishing between trips for transportation, trips to school (i.e., walking and cycling for transportation between 07:00-09:00 AM on school days (one-way trip)) and trips for recreation (i.e., walking and cycling during playing outdoors and walking the dog).

\subsection{Background Variables}

Other variables that were collected at the individual level included: age, sex, body height and body weight of the child, maternal and paternal education level (low: primary school or lower vocational training; medium: secondary school or intermediate vocational training; high: higher vocational training or university), and country of origin of the child and both parents. Body height and body weight were measured by two trained research assistants with a portable stadiometer (Stanley 04-116) and a digital scale (Seca 812), respectively, while the child was wearing clothes but no shoes. Body mass index (BMI) was calculated $\left(\mathrm{kg} / \mathrm{m}^{2}\right)$ and categorized into normal weight, overweight, and obesity (excluding overweight) according to international age- and sex-specific cut-off points [33]. Children were categorized into Dutch, Turkish, Moroccan, Surinam/ Antillean, other Western, and other nonWestern ethnic groups. They were only categorized as Dutch if the child and both parents were born in the Netherlands.

\subsection{Independent Variables: Built Environmental Characteristics}

Built environmental characteristics were collected by neighborhood observation. Two trained research assistants walked through the neighborhoods after school time and together completed one checklist in unison. The checklist is based on the Neighborhood Environment Walkability Scale [34] but was modified to reflect the Dutch built environment, including items relevant to children (e.g., playgrounds, school yards, and dog waste), as identified by focus group interviews prior to the study [35]. The inter-rater reliability of the checklist was evaluated as good (percentage of agreement = $77 \%$ ) in a later study [36]. The checklist consists of 54 items on type of residences, sports facilities, recreation facilities, play facilities, green space, water, dirt, traffic safety, walking and cycling infrastructure, and general impression of the activity-friendliness of the neighborhood [22]. Type of residences (8 items) were weighted and summed per neighborhood to estimate residential density [34]. The number of sports facilities (12 items), recreation facilities (3 items), and play facilities (4 items), and the scores on the presence of dirt ( 2 items) and traffic safety ( 5 items) were also summed per neighborhood. The remaining items were analyzed separately. These included: proportion of residents to enterprises, proportion of green space to residents, frequency of unoccupied houses (scoring: 1 [none]-5 [all]), presence of green space (scoring: 1 [no]-4 [much]), presence of water (scoring: 
1 [no]-4 [much]), frequency of 14 items on walking and cycling infrastructure (i.e., sidewalks, cycle-tracks, zebra crossings, pedestrian crossings, traffic lights, traffic islands, parking garages, parallel parking spaces, parking lots, speed bumps, 30-km speed zones, low-traffic zones, roundabouts, and intersections; scoring: 1 [few] -3 [many]), and general impression of the activity-friendliness of the neighborhood (scoring: 1-10).

\subsection{Statistical Analyses}

Fifty-one percent $(n=625)$ of the original sample returned the physical activity diary. Children failing to complete the diary for at least three school days $(n=68)$ and children with missing data on age, sex, parental education level $(n=108)$, and/ or ethnicity $(n=82)$ were excluded from analyses. The final sample consisted of 448 children. This sample was older than the original sample of 1,228 children $(8.3 \pm 1.5$ year old versus $7.8 \pm 1.5$ year old; $\mathrm{t}=-5.585 ; \mathrm{df}=1,226 ; \mathrm{p}<0.001)$ and more often of Dutch origin $\left(\chi^{2}=44.003\right.$; $\left.\mathrm{df}=1 ; \mathrm{p}<0.001\right)$. No significant differences were found in sex and parental education level between the final and original samples.

Univariate and multivariate linear regression analyses were conducted in SPSS 14.0 to examine the association between 23 of the 26 built environmental characteristics and the number of walking and cycling trips per week. The following three built environmental characteristics were excluded from analysis because of insufficient variance between neighborhoods: the frequency of parking garages, speed bumps, and low-traffic zones. Dependent variables were: walking and cycling for transportation (model 1), walking and cycling to school (model 2), and walking and cycling for recreation (model 3). Walking and cycling were examined jointly and separately. First, the association between children's walking and cycling behavior and built environmental characteristics were examined in separate models since the environmental characteristics may be correlated. After crude analyses, all models were adjusted for age, sex, parental education level, and ethnicity [13]. Built environmental characteristics that reached significance $(\mathrm{p} \leq 0.05)$ in the adjusted univariate linear regression analyses were included in the multivariate linear backward regression analyses. Regression coefficients (B) and 95\% confidence intervals (CI) were calculated. Although clustering of subjects within neighborhoods was limited (i.e., intra cluster correlation $(\mathrm{ICC})=0.02)$, multilevel analyses were also conducted.

\section{Results and Discussion}

\subsection{Results}

The final sample consisted of 216 boys and 232 girls with a mean age of $8.3 \pm 1.5$ years (Table 2). Twenty-eight percent of the children were overweight or obese. The majority of the children was of Dutch origin and had parents with a medium education level. All 10 neighborhoods were represented in the final sample. The number of participants per neighborhood ranged between two and 108, with an average of 45 children. 
Table 2. Background characteristics of the sample $(n=448)$.

\begin{tabular}{|c|c|}
\hline Sex & $\%$ \\
\hline Boys & 48 \\
\hline Girls & 52 \\
\hline Age & year \\
\hline Mean & 8.3 \\
\hline Standard deviation & 1.5 \\
\hline BMI (body mass index) & $\%$ \\
\hline Normal weight & 72 \\
\hline Overweight & 20 \\
\hline Obesity & 8 \\
\hline Origin & $\%$ \\
\hline Dutch & 61 \\
\hline Turkish & 13 \\
\hline Moroccan & 6 \\
\hline Surinam/ Antillean & 6 \\
\hline Other Western & 6 \\
\hline Other non-Western & 8 \\
\hline Maternal education & $\%$ \\
\hline Low & 27 \\
\hline Medium & 56 \\
\hline High & 17 \\
\hline Paternal education & $\%$ \\
\hline Low & 33 \\
\hline Medium & 42 \\
\hline High & 24 \\
\hline Neighborhoods & $\mathrm{n}$ \\
\hline Delftwijk, Haarlem & 26 \\
\hline Molenwijk, Haarlem & 63 \\
\hline Spangen, Rotterdam & 35 \\
\hline Nieuwe Westen, Rotterdam & 31 \\
\hline Randenbroek-Schuilenburg, Amersfoort & 46 \\
\hline Liendert, Amersfoort & 67 \\
\hline Groenoord, Schiedam & 2 \\
\hline Holy-Zuid, Vlaardingen & 108 \\
\hline Berflo Es, Hengelo & 60 \\
\hline Wilderinkshoek-Tuindorp, Hengelo & 10 \\
\hline
\end{tabular}

Ninety-three percent of the children walked or cycled for transportation at least once per week. Walking or cycling to school was reported by $82 \%$ of the children. Of those children, $53 \%$ walked and $40 \%$ cycled to school on every school day. Twenty-five percent of the children walked for recreation at least once per week. Cycling for recreation was not reported. On average, the children made $13.3 \pm 10.7$ walking and $6.6 \pm 9.2$ cycling trips per week for transportation; $3.6 \pm 3.2$ walking and $1.5 \pm 2.6$ cycling trips per week to school; and $0.7 \pm 2.0$ walking trips per week for recreation. Significant differences were found between the neighborhoods in the use of walking and cycling for 
transportation, and walking and cycling to school (walking for transportation: range $=7.7-20.1$ trips per week; $\mathrm{F}=3.338 ; \mathrm{df}=9 ; \mathrm{p}=0.001$, cycling for transportation: range $=0.6-12.6$ trips per week; $\mathrm{F}=8.970 ; \mathrm{df}=9 ; \mathrm{p}<0.001$, walking to school: range $=2.1-5.8$ trips per week $\mathrm{F}=3.346 ; \mathrm{df}=9 ;$ $\mathrm{p}=0.001$, cycling to school: range $=0.0-3.5$ trips per week; $\mathrm{F}=7.602 ; \mathrm{df}=9 ; \mathrm{p}<0.001$ ) (Figure 1a and 1b). No significant differences were found between neighborhoods in the frequency of walking for recreation (range $=0.0-1.7$ trips per week).

Figure 1. (a) Walking behavior per neighborhood: red = walking to school; yellow = walking for transportation (excluding to school); blue = walking for recreation. (b) Cycling behavior per neighborhood: red = cycling to school; yellow = cycling for transportation excluding to school.

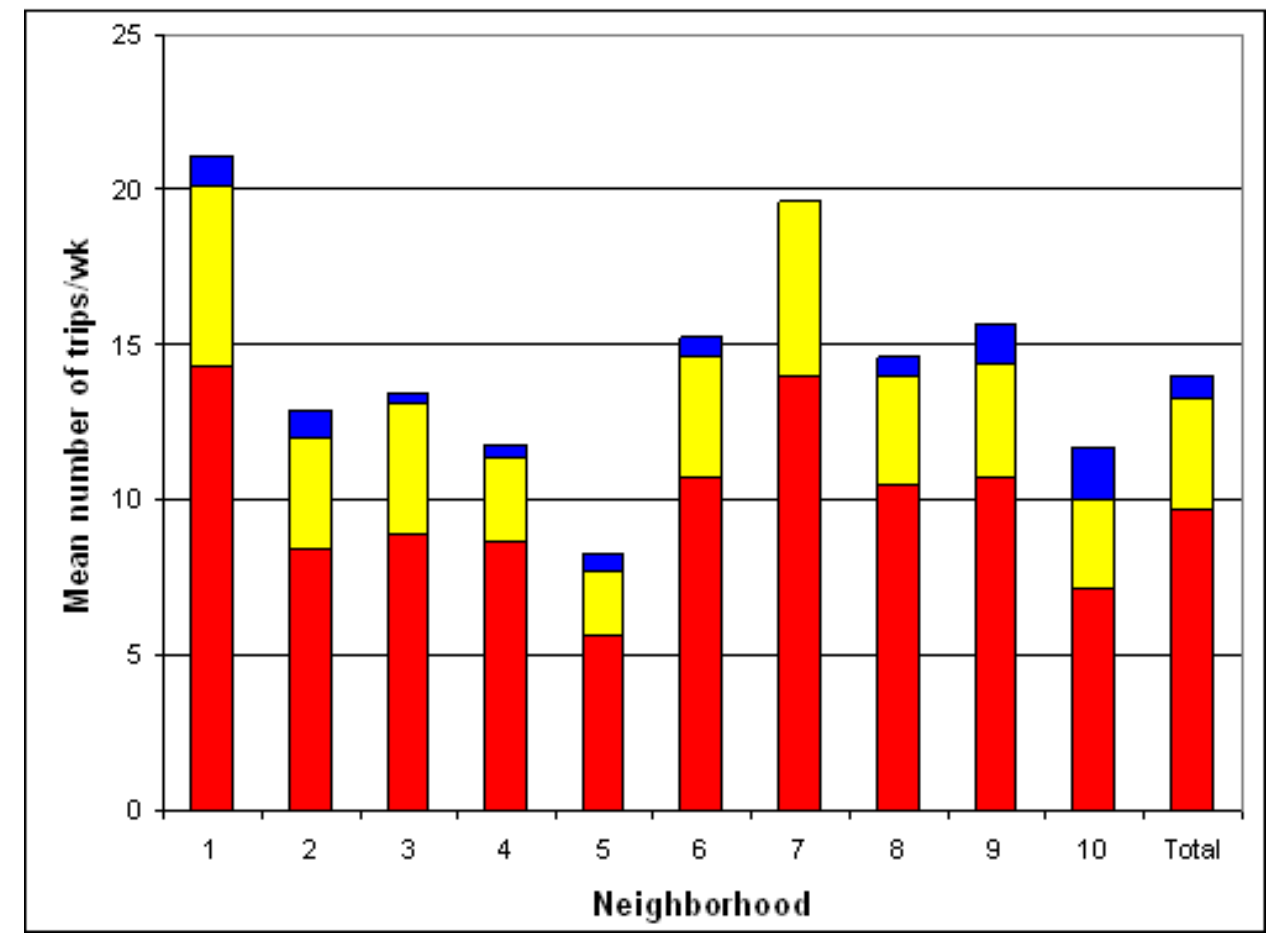

(a)

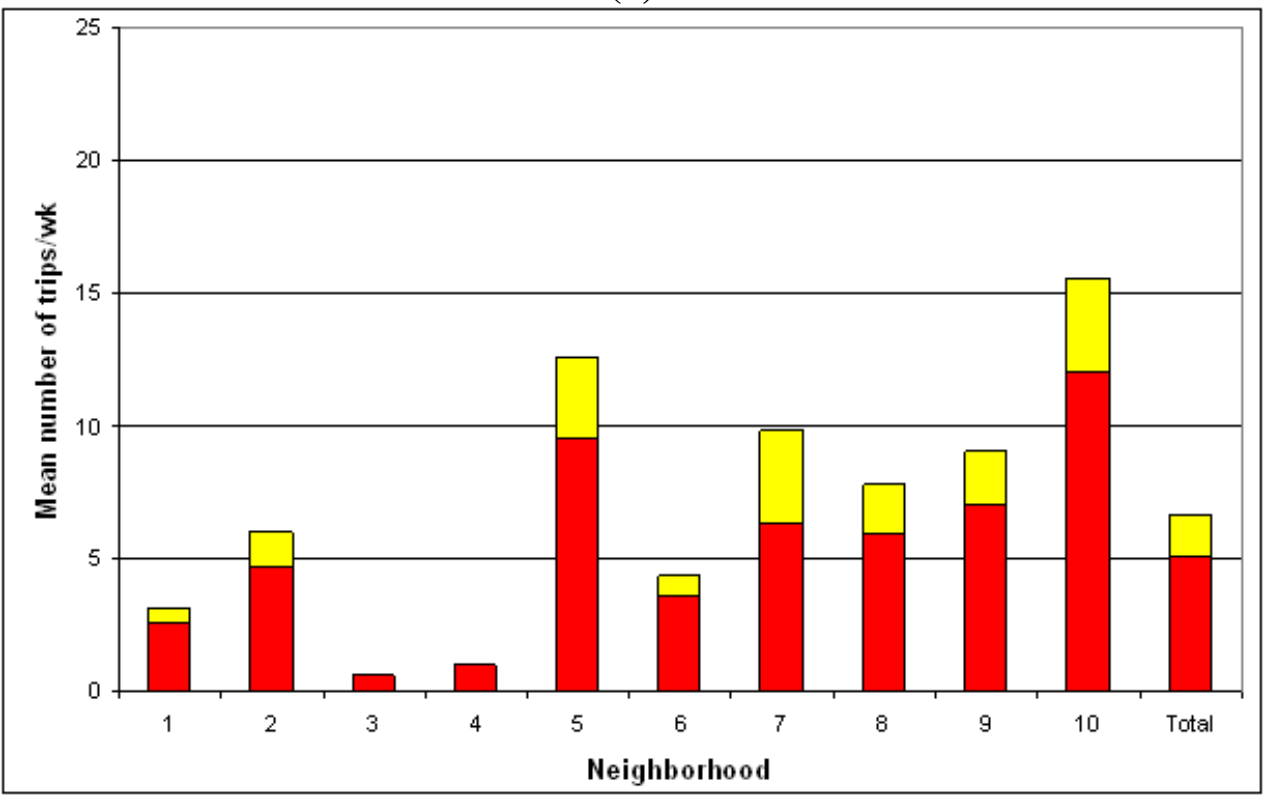

(b) 
Univariate linear regression analyses showed that 15 of the 23 built environmental characteristics under study were significantly associated with walking or cycling for transportation or walking or cycling to school. These included: recreation and play facilities, green space, water, traffic safety, and items on the walking and cycling infrastructure. When these characteristics were entered in a multivariate model, total walking and cycling for transportation were strongest associated with the presence of water and the frequency of sidewalks in the neighborhood $\left(\mathrm{R}^{2}=34.3 \%\right)$ (Table 3 ). Sidewalks remained significantly associated with total walking and cycling for transportation in a multilevel model $(\mathrm{B}=7.41 ; 95 \% \mathrm{CI}=0.41-14.42$; $\mathrm{p}<0.05)$. However, when walking and cycling for transportation were analyzed separately, different built environmental correlates were found. Walking for transportation was strongest associated with the frequency of cycle-tracks, traffic lights, and roundabouts in the neighborhood in a multivariate model $\left(\mathrm{R}^{2}=29.9 \%\right)$. For cycling for transportation, correlates were the number of recreation facilities, traffic safety, and the frequency of sidewalks, pedestrian crossings, traffic lights, parallel parking spaces, and parking lots in the neighborhood $\left(\mathrm{R}^{2}=33.2 \%\right)$. In multilevel analyses, traffic lights and roundabouts remained associated with walking for transportation $(\mathrm{B}=-7.16 ; 95 \% \mathrm{CI}=-17.85--3.53 ; \mathrm{p}<0.10 ; \mathrm{B}=11.55 ; 95 \% \mathrm{CI}=1.49-24.51$; $\mathrm{p}<0.10$, respectively). For cycling for transportation, significant correlates were the number of recreation facilities $(\mathrm{B}=1.84 ; 95 \% \mathrm{CI}=0.05-3.64 ; \mathrm{p}<0.05)$ and the frequency of pedestrian crossings $(\mathrm{B}=14.53 ;-3.91-32.96 ; \mathrm{p}<0.10)$ in a multilevel model. Comparable results were found for walking and cycling to school. Total walking and cycling to school were strongest associated with the frequency of cycle-tracks in the neighborhood in a multivariate model $\left(\mathrm{R}^{2}=33.4 \%\right)$, whereas walking to school was strongest associated with the presence of green space and the frequency of pedestrian crossings, parallel parking spaces, parking lots, and roundabouts in the neighborhood $\left(\mathrm{R}^{2}=30.0 \%\right)$, and cycling to school was strongest associated with the number of recreation facilities, the presence of green space, and the frequency of pedestrian crossings, traffic lights, and parallel parking spaces in the neighborhood $\left(\mathrm{R}^{2}=30.6 \%\right)$. The environmental correlations observed for the total of walking and cycling to school as well as those of walking to school all remained significantly associated in multilevel analyses (i.e., frequency of cycle-tracks: $\mathrm{B}=1.32 ; 95 \% \mathrm{CI}=-0.05-2.69 ; \mathrm{p}<0.10$; green space: $\mathrm{B}=-2.59 ; 95 \% \mathrm{CI}=-3.67--1.50 ; \mathrm{p}<0.01$; pedestrian crossings: $\mathrm{B}=6.54 ; 95 \% \mathrm{CI}=3.51-$ 9.56; $\mathrm{p}<0.01$; parallel parking spaces: $\mathrm{B}=2.80$; 95\% $\mathrm{CI}=1.64-3.96 ; \mathrm{p}<0.01$; parking lots: $\mathrm{B}=2.75 ; 95 \% \mathrm{CI}=1.58-3.91 ; \mathrm{p}<0.01$; roundabouts: $\mathrm{B}=4.31 ; 95 \% \mathrm{CI}=2.67-5.96 ; \mathrm{p}<0.01$ ). For cycling to school, only the number of recreation facilities remained significantly associated in a multilevel model ( $\mathrm{B}=0.40 ; 95 \% \mathrm{CI}=0.11-0.69 ; \mathrm{p}<0.05)$. None of the built environmental characteristics under study were significantly associated with walking for recreation. 
Table 3. Adjusted multivariate models of the association between built environmental characteristics and children's walking and cycling behavior.

\begin{tabular}{|c|c|c|c|c|c|c|c|}
\hline \multirow{2}{*}{$\begin{array}{l}\text { Built environmental } \\
\text { characteristic }\end{array}$} & \multirow{2}{*}{ Range } & \multicolumn{6}{|c|}{$\begin{array}{c}\text { B } \\
95 \% \mathrm{CI} \\
\end{array}$} \\
\hline & & $\begin{array}{l}\text { Walking and cycling for } \\
\text { transportation }_{1}\end{array}$ & $\begin{array}{l}\text { Walking for } \\
\text { transportation }_{1 \mathrm{a}}\end{array}$ & $\begin{array}{l}\text { Cycling for } \\
\text { transportation } \\
1 \mathrm{~b}\end{array}$ & $\begin{array}{l}\text { Walking and } \\
\text { cycling to school } 2\end{array}$ & $\begin{array}{l}\text { Walking to } \\
\text { school }_{2 \mathrm{a}}\end{array}$ & $\begin{array}{l}\text { Cycling to } \\
\text { school }_{2 \mathrm{~b}}\end{array}$ \\
\hline Play facilities & $2-12$ & & & & & & \\
\hline Recreation facilities & $0-11$ & & & $\begin{array}{c}1.66^{* *} \\
0.46,2.86 \\
\end{array}$ & & & $\begin{array}{c}0.41 * * \\
0.19,0.63 \\
\end{array}$ \\
\hline Green space & $2-3$ & & & & & $\begin{array}{c}-2.05 * * \\
-3.20,-0.91\end{array}$ & $\begin{array}{c}0.52 \\
-0.27,1.30 \\
\end{array}$ \\
\hline $\begin{array}{l}\text { Proportion green space } \\
\text { to residents }\end{array}$ & $5-40$ & & & & & & \\
\hline Water & $1-3$ & $\begin{array}{c}1.56 \\
-2.71,5.82 \\
\end{array}$ & & & & & \\
\hline Traffic safety & $0-6$ & & & $\begin{array}{c}0.08 \\
-1.11,1.27 \\
\end{array}$ & & & \\
\hline Sidewalks & $2-3$ & $\begin{array}{c}6.43^{*} \\
1.32,11.53\end{array}$ & & $\begin{array}{c}-2.14 \\
-9.00,4.71\end{array}$ & & & \\
\hline Cycle-tracks & $1-2$ & & $\begin{array}{c}3.45 \\
-0.21,7.12 \\
\end{array}$ & & $\begin{array}{c}1.12^{*} \\
0.18,2.05\end{array}$ & & \\
\hline Pedestrian crossings & $1-2$ & & & $\begin{array}{c}14.66 * * \\
5.96,23.36 \\
\end{array}$ & & $\begin{array}{c}4.85 * * \\
1.65,8.04 \\
\end{array}$ & $\begin{array}{c}3.41 * * \\
1.49,5.33 \\
\end{array}$ \\
\hline Traffic lights & $1-2$ & & $\begin{array}{c}-7.29 * * \\
-10.71,-3.87 \\
\end{array}$ & $\begin{array}{c}-1.385 \\
-6.625,3.855 \\
\end{array}$ & & & $\begin{array}{c}-0.59 \\
-1.61,0.43 \\
\end{array}$ \\
\hline Traffic islands & $1-2$ & & & & & & \\
\hline
\end{tabular}


Table 3. Cont.

\begin{tabular}{|c|c|c|c|c|c|}
\hline Parallel parking spaces & $1-3$ & & $\begin{array}{c}6.52 * \\
1.18,11.86\end{array}$ & $\begin{array}{c}2.29 * * \\
1.08,3.51\end{array}$ & $\begin{array}{c}1.46 * * \\
0.38,2.55\end{array}$ \\
\hline Parking lots & $1-3$ & & & $\begin{array}{c}2.35 * * \\
1.13,3.56\end{array}$ & \\
\hline Roundabouts & $1-2$ & $\begin{array}{c}11.14 * * \\
6.35,15.94\end{array}$ & & $\begin{array}{c}3.59 * * \\
1.80,5.39\end{array}$ & \\
\hline Intersections & $1-3$ & & & & \\
\hline
\end{tabular}

B corresponds with the increase or decrease of the number of walking or cycling trips per week with an increase of one unit in the particular built environmental characteristics, independent of other characteristics in the model;

$\mathrm{CI}=$ confidence interval;

$* \mathrm{p}<0.05$

$* * \mathrm{p}<0.01$

model 1: $\mathrm{R}^{2}=34.3 \%$;

model 1a: $\mathrm{R}^{2}=29.9 \%$;

model $1 \mathrm{~b}: \mathrm{R}^{2}=33.2 \%$;

model 2: $\mathrm{R}^{2}=33.4 \%$;

model 2a: $\mathrm{R}^{2}=30.0 \%$;

model $2 \mathrm{~b}: \mathrm{R}^{2}=30.6 \%$. 


\subsection{Discussion}

The purpose of this study was to identify built environmental characteristics that were associated with children's walking and cycling behavior and to examine whether there are differences by purpose (transportation, school, and recreation) and by commuting mode (walking, cycling, and combined). Ninety-four percent of the children in this study walked or cycled at least once per week. Although this is a high percentage compared to other countries, only a small percentage of the children (less than $10 \%$ ) walked or cycled every day. Changes in the built environment may increase children's walking and cycling behavior [37]. In our study, a number of built environmental factors were found to correlate with children's walking and cycling behavior. Although small differences were found between the built environmental correlates of walking and those of cycling, both commuting modes were positively associated with the frequency of pedestrian crossings and the frequency of parallel parking spaces in the neighborhood. More differences were found in built environmental correlates of walking and cycling for different purposes. Whereas none of the built environmental characteristics under study were significantly associated with walking for recreation, a considerable proportion of the variance in walking and cycling for transportation and walking and cycling to school could be explained by built environmental characteristics. Adjusted multivariate models showed that about $30 \%$ of the variance in walking and cycling for transportation could be explained by the number of recreation facilities in the neighborhood and the walking and cycling infrastructure of the neighborhood. Comparable correlations were found for walking and cycling to school.

The results of our study are in line with studies among adults and adolescents, in which behavior specific built environmental factors correlating with walking and cycling were also found [27-29]. Carver et al. [27] found differences between the built environmental factors correlating with cycling for recreation, cycling for transportation, and cycling to/from school, and of walking for exercise, walking for transportation, walking to school, and walking the dog among Australian adolescents. Walking for transportation was associated with local traffic volume and stores near home. Cycling for transportation on the other hand, was associated with having good sports facilities. For walking and cycling to school, Carver et al. [27] found no significant associations, except for girls walking to school. For girls, parents' concern about busy traffic was negatively associated with walking to school. From a review of environmental studies on walking among adults [28], it was concluded that built environmental characteristics associated with walking for exercise are different from those associated with walking for transportation. For cycling among adults, comparable conclusions can be drawn [29].

Although in our study, built environmental correlates of children's walking and cycling behavior differed by purpose, there were also points of similarity. Both walking and cycling for transportation, walking and cycling to school, and walking for recreation were not associated with the residential density, type of residences, presence of dirt or the general impression of the activity friendliness of the neighborhood. Built environmental characteristics most consistently associated with walking and cycling for transportation and walking and cycling to school were the frequency of pedestrian crossings and parallel parking spaces in the neighborhood. In previous studies, the walking and cycling infrastructure of a neighborhood was also shown to be important $[13,17,19]$. For example, in the United States, Kerr et al. [20] found a positive association between perceived walking and cycling facilities (e.g., sidewalks, walking and cycling trails) within $1-\mathrm{km}$ of the child's residence and the 
objective walkability of the neighborhood. Hume et al. [19] found that adolescents whose parent perceived there to be insufficient traffic lights and pedestrian crossings in their neighborhood were less likely to increase their walking or cycling behavior to school in a two year period.

The positive association between the frequency of parallel parking spaces in the neighborhood and cycling for transportation, and walking and cycling to school in our study, might be explained by a lower speed of motorists in narrow streets [38]. In our study, the parallel parking spaces were frequently found in neighborhoods with $30-\mathrm{km}$ speed zones (correlation coefficient $\mathrm{r}=0.64$; $\mathrm{p}<0.001)$, sport fields $(\mathrm{r}=0.62 ; \mathrm{p}<0.001)$, and less heavy lorry and bus traffic $(\mathrm{r}=-0.65 ; \mathrm{p}<0.001)$. Children may also feel safer when walking on the sidewalk; because of the barrier the parked cars create [35].

In this study, no associations were found between environmental characteristics of the neighborhood and walking for recreation. Perhaps walking for recreation takes place outside the boundaries of the neighborhood or perhaps other factors are important, such as children's and parents' perceptions of traffic safety, personal safety, and social interaction [19,20,27,39].

\subsection{Limitations and Strengths}

Our study had a cross-sectional design restricting the interpretation of directions of associations. However, in due course, measurements will be repeated after spatial restructuring of five of the 10 neighborhoods to examine the effects of environmental changes on children's physical activity level. A second limitation is the limited variance in the built environment between the 10 neighborhoods. All neighborhoods were relatively deprived. Any future study should be extended to more rural neighborhoods to add variance.

This study is among the first to examine the association between the built environment and children's walking and cycling behavior by purpose, and by commuting mode. Improving the walking and cycling infrastructure of neighborhoods (i.e., building more pedestrian crossings and providing parallel parking spaces) may help to increase active transportation among children. However, one has to keep in mind that walkable neighborhoods are not necessarily cyclable neighborhoods (and vice versa), and neighborhoods which are very suitable for walking and cycling for transportation are not necessarily suitable for walking and cycling for recreation. Therefore, a behavior specific approach is recommended for interventions and future studies. Furthermore, future studies should explore the relative importance of, and the interaction between, individual, social environmental, built environmental, and natural environmental determinants of children's walking and cycling behavior. Next, further research requires longitudinal and intervention studies, utilizing multilevel design methodologies. Since environmental characteristics are thought to have the potential to influence behavior without individuals being consciously aware of them, it is recommended to assess both perceived and objective characteristics of the built environment in the same study [40]. Objective measures of built environmental characteristics can be integrated in a geographic information system (GIS) $[9,13,41,42]$. In addition, the use of global position systems (GPS) can increase our understanding of children's walking and cycling behavior, for example by providing an insight into walking and cycling routes to school $[43,44]$. Combining different subjective and objective measures of physical activity with different perceived and objective measures of the built environment will result 
in a picture of where, when, and how long children are exposed to certain built environmental characteristics and how these characteristics influence their walking and cycling behavior.

\section{Conclusions}

In this study, a broad array of potentially relevant characteristics of the Dutch built environment that may either encourage or discourage walking and cycling among children have been examined. The results showed that built environmental correlates of children's walking and cycling behavior differ by purpose (transportation, school, and recreation) and by commuting mode (walking, cycling, and combined). In general, the higher the frequency of pedestrian crossings and the higher the frequency of parallel parking spaces in the neighborhood, the higher the number of walking and cycling trips for transportation purposes. In order to examine whether changing the traffic infrastructure of a neighborhood will actually lead to more walking and cycling among children, repeated measurements are required.

\section{Acknowledgements}

This study was supported by a grant from the Dutch Ministry of Health, Welfare and Sport and the Dutch Ministry of Housing, Spatial Planning and the Environment. We appreciate the enthusiastic cooperation of the teachers, principals, parents, and children who were involved in this study. The authors thank Joanne Huizinga, Tijmen Companjen, and Steffin Nauta for their assistance during data collection.

\section{References}

1. Dollman, J.; Norton, K.; Norton, L. Evidence for secular trends in children's physical activity behaviour. Br. J. Sports Med. 2005, 39, 892-897.

2. McDonald, N.C. Active transportation to school: trends among U.S. schoolchildren, 1969-2001. Am. J. Prev. Med. 2007, 32, 509-516.

3. van der Ploeg, H.P.; Merom, D.; Corpuz, G.; Bauman, A.E. Trends in Australian children traveling to school 1971-2003: burning petrol or carbohydrates? Prev. Med. 2008, 46, 60-62.

4. Buliung, R.N.; Mitra, R.; Faulkner, G. Active school transportation in the Greater Toronto Area, Canada: an exploration of trends in space and time (1986-2006). Prev. Med. 2009, 48, 507-512.

5. Davison, K.K.; Werder, J.L.; Lawson, C.T. Children's active commuting to school: current knowledge and future directions. Prev. Chronic. Dis. 2008, 5, A100.

6. Faulkner, G.E.; Buliung, R.N.; Flora, P.K.; Fusco, C. Active school transport, physical activity levels and body weight of children and youth: a systematic review. Prev. Med. 2009, 48, 3-8.

7. Tudor-Locke, C.; Ainsworth, B.E.; Popkin, B.M. Active commuting to school: an overlooked source of children's physical activity? Sports Med. 2001, 31, 309-313.

8. Pikora, T.; Giles-Corti, B.; Bull, F.; Jamrozik, K.; Donovan, R. Developing a framework for assessment of the environmental determinants of walking and cycling. Soc. Sci. Med. 2003, 56, 1693-1703.

9. Panter, J.R.; Jones, A.P.; van Sluijs, E.M.; Griffin, S.J. Neighborhood, Route, and School Environments and Children's Active Commuting. Am. J. Prev. Med. 2010, 38, 268-278. 
10. Salmon, J.; Salmon, L.; Crawford, D.A.; Hume, C.; Timperio, A. Associations among individual, social, and environmental barriers and children's walking or cycling to school. Am. J. Health Promot. 2007, 22, 107-113.

11. Timperio, A.; Ball, K.; Salmon, J.; Roberts, R.; Giles-Corti, B.; Simmons, D.; Baur, L.A.; Crawford, D. Personal, family, social, and environmental correlates of active commuting to school. Am. J. Prev. Med. 2006, 30, 45-51.

12. Larsen, K.; Gilliland, J.; Hess, P.; Tucker, P.; Irwin, J.; He, M. The influence of the physical environment and sociodemographic characteristics on children's mode of travel to and from school. Am. J. Public Health 2009, 99, 520-526.

13. Pont, K.; Ziviani, J.; Wadley, D.; Bennett, S.; Abbott, R. Environmental correlates of children's active transportation: a systematic literature review. Health Place 2009, 15, 827-840.

14. Evenson, K.R.; Birnbaum, A.S.; Bedimo-Rung, A.L.; Sallis, J.F.; Voorhees, C.C.; Ring, K.; Elder, J.P. Girls' perception of physical environmental factors and transportation: reliability and association with physical activity and active transport to school. Int. J. Behav. Nutr. Phys. Act. 2006, 3, 28.

15. McMillan, T.E. The relative influence of urban form on a child's travel mode to school. Transp. Res. A 2007, 41, 69-79.

16. Hume, C.; Salmon, J.; Ball, K. Associations of children's perceived neighborhood environments with walking and physical activity. Am. J. Health Promot. 2007, 21, 201-207.

17. Bringolf-Isler, B.; Grize, L.; Mader, U.; Ruch, N.; Sennhauser, F.H.; Braun-Fahrlander, C. Personal and environmental factors associated with active commuting to school in Switzerland. Prev. Med. 2008, 46, 67-73.

18. Merom, D.; Tudor-Locke, C.; Bauman, A.; Rissel, C. Active commuting to school among NSW primary school children: implications for public health. Health Place 2006, 12, 678-687.

19. Hume, C.; Timperio, A.; Salmon, J.; Carver, A.; Giles-Corti, B.; Crawford, D. Walking and cycling to school: predictors of increases among children and adolescents. Am. J. Prev. Med. 2009, 36, 195-200.

20. Kerr, J.; Rosenberg, D.; Sallis, J.F.; Saelens, B.E.; Frank, L.D.; Conway, T.L. Active commuting to school: Associations with environment and parental concerns. Med. Sci. Sports Exerc. 2006, 38, 787-794.

21. Ferreira, I.; van der Horst, K.; Wendel-Vos, W.; Kremers, S.; van Lenthe, F.J.; Brug, J. Environmental correlates of physical activity in youth-a review and update. Obes. Rev. 2007, 8 , 129-154.

22. de Vries, S.I.; Bakker, I.; van Mechelen, W.; Hopman-Rock, M. Determinants of activity-friendly neighborhoods for children: results from the SPACE study. Am. J. Health Promot. 2007, 21, 312-316.

23. Wendel-Vos, W.; Droomers, M.; Kremers, S.; Brug, J.; van Lenthe, F. Potential environmental determinants of physical activity in adults: a systematic review. Obes. Rev. 2007, 8, 425-440.

24. van der Houwen, K.; Goossen, J.; Veling, I. Travel behavior of elementary school children. Fietsverkeer 2003, 3, 4-6. (In Dutch)

25. Nelson, N.M.; Foley, E.; O’Gorman, D.J.; Moyna, N.M.; Woods, C.B. Active commuting to school: How far is too far? Int. J. Behav. Nutr. Phys. Act. 2008, 5, 1. 
26. Dutch National Travel Survey 2006. (Public database analyzed by S.I. de Vries in 2007). Available online: http://www.rws.nl/wegen/innovatie_en_onderzoek/betere_doorstroming/ mobiliteitsonderzoek_nederland/documenten/ (accessed May 2010).

27. Carver, A.; Salmon, J.; Campbell, K.; Baur, L.; Garnett, S.; Crawford, D. How do perceptions of local neighborhood relate to adolescents' walking and cycling? Am. J. Health Promot. 2005, 20, 139-147.

28. Owen, N.; Humpel, N.; Leslie, E.; Bauman, A.; Sallis, J.F. Understanding environmental influences on walking; Review and research agenda. Am. J. Prev. Med. 2004, 27, 67-76.

29. Wendel-Vos, G.C.; Schuit, A.J.; de Niet, R.; Boshuizen, H.C.; Saris, W.H.; Kromhout, D. Factors of the physical environment associated with walking and bicycling. Med. Sci. Sports Exerc. 2004, 36, 725-730.

30. Giles-Corti, B.; Timperio, A.; Bull, F.; Pikora, T. Understanding physical activity environmental correlates: increased specificity for ecological models. Exerc. Sport Sci. Rev. 2005, 33, 175-181.

31. Wendel-Vos, G.C.W.; Schuit, A.J.; Seidel, J.C. Implications of Policy Measures from the 'Nota Wonen' Concerning Physical Inactivity in the Netherlands. Part of the Health Effect Report "People Want Healthy Living"; RIVM: Bilthoven, the Netherlands, 2002; pp. 29-36. (In Dutch)

32. de Vries, S.I.; Hopman-Rock, M.; Bakker, I.; van Mechelen, W. Meeting the 60-minute physical activity guideline: effect of operationalisation. Med. Sci. Sports Exerc. 2009, 41, 81-86.

33. Cole, T.J.; Bellizzi, M.C.; Flegal, K.M.; Dietz, W.H. Establishing a standard definition for child overweight and obesity worldwide: international survey. Br. Med. J. 2000, 320, 1240-1243.

34. Saelens, B.E.; Sallis, J.F.; Black, J.B.; Chen, D. Neighborhood-based differences in physical activity: an environment scale evaluation. Am. J. Public Health 2003, 93, 1552-1558.

35. de Vries, S.I.; Bakker, I.; van Overbeek, K.; Boer, N.D.; Hopman-Rock, M. Children from Priority Neighbourhoods: Physical (In)activity and Overweight; TNO Quality of Life: Leiden, The Netherlands, 2005; pp. 27-38. (In Dutch)

36. Bakker, I.; de Vries, S.I.; van den Boogaard, C.M.H.; van Hirtum, W.J.E.M.; Joore, J.P.; Jongert, M.W.A. Playground of the Future: Successful Playgrounds for Primary School Children; TNO Quality of Life: Leiden, the Netherlands, 2008; pp. 17-24. (In Dutch)

37. Boarnet, M.G.; Anderson, C.L.; Day, K.; McMillan, T.; Alfonzo, M. Evaluation of the California Safe Routes to School legislation: urban form changes and children's active transportation to school. Am. J. Prev. Med. 2005, 28, 134-140.

38. Pucher, J.; Dijkstra, L. Promoting safe walking and cycling to improve public health: lessons from The Netherlands and Germany. Am. J. Public. Health 2003, 93, 1509-1516.

39. Timperio, A.; Crawford, D.; Telford, A.; Salmon, J. Perceptions about the local neighborhood and walking and cycling among children. Prev. Med. 2004, 38, 39-47.

40. Kremers, S.P.; de Bruijn, G.J.; Visscher, T.L.; van Mechelen, W.; de Vries, N.K.; Brug, J. Environmental influences on energy balance-related behaviors: a dual-process view. Int. J. Behav. Nutr. Phys. Act. 2006, 3, 9.

41. McCormack, G.; Giles-Corti, B.; Lange, A.; Smith, T.; Martin, K.; Pikora, T.J. An update of recent evidence of the relationship between objective and self-report measures of the physical environment and physical activity behaviours. J. Sci. Med. Sport 2004, 7, 81-92. 
42. Davison, K.K.; Lawson, C.T. Do attributes in the physical environment influence children's physical activity? A review of the literature. Int. J. Behav. Nutr. Phys. Act. 2006, 3, 19.

43. Duncan, M.J.; Badland, H.M.; Mummery, W.K. Applying GPS to enhance understanding of transport-related physical activity. J. Sci. Med. Sport 2009, 12, 549-556.

44. Mackett, R.; Brown, B.; Gong, Y.; Kitazawa, K.; Paskins, J. Children's independent movement in the local environment. Built Environ. 2007, 33, 454-468.

(C) 2010 by the authors; licensee MDPI, Basel, Switzerland. This article is an open-access article distributed under the terms and conditions of the Creative Commons Attribution license (http://creativecommons.org/licenses/by/3.0/). 